\title{
Comprehensive Geriatric Assessment in a Mexican Long-term Care Facility During a COVID-19 Outbreak
}

\author{
(1) Fernando Coindreau-Frías'1, (1) Juan de Dios Garza-Rivera22, (1) Luis E. Fernández-Garza ${ }^{3}$, (1) Javier Valero-Gomez 4 \\ ${ }_{1}^{1}$ Geriatrics/Medical Director Casa de Reposo Luis Elizondo A.C. Guadalupe, Nuevo León, Mexico \\ 2 Geriatrics Fellowship, Mexican Institute of Social Security, HGZ 4, Guadalupe, Nuevo León, Mexico \\ ${ }^{3}$ Headache and Chronic Pain Clinic, Department of Neurology, University Hospital "Dr. José Eleuterio González", Autonomous University of Nuevo \\ León, Nuevo León, Mexico \\ ${ }^{4}$ Counselor Asilo Luis Elizondo A.C./Medical Director Christus Muguerza Hospital Sur, Nuevo León, Mexico
}

\begin{abstract}
Objective: The Coronavirus disease-2019 (COVID-19) pandemic has greatly affected long-term care facilities worldwide. In Mexico, there are no studies that assess the impact between COVID-19 and the comprehensive geriatric assessment (CGA). This article aims to investigate the effect on the geriatric assessment before and after COVID-19 infection had in residents of a long-term care facility, as well as the factors that influenced the virus transmission and its associated mortality.
\end{abstract}

Materials and Methods: This is a prospective observational study that included 90 older adults during an outbreak of COVID-19 in a long-term care facility in Monterrey, Nuevo León, Mexico. Participants' geriatric assessments were designed using their history records, comorbidities and Barthel index, Folstein's mini-mental state examination, geriatric depression scale, mini nutritional assessment, and polypharmacy.

Results: When comparing the CGA before and after the COVID-19, Barthel index median was 90 vs 57.7 ( $p=0.001$ ), the mini-mental state examination median was 23 vs $19(p=0.001)$, the geriatric depression scale median was 4 vs $5(p=0.007)$, the weight mean was 59.63 vs 56.95 ( $p=0.001)$, the body mass index mean was 23.9 vs 23.19 ( $p=0.009$ ), and the mini nutritional assessment median was 23 vs 21.5 ( $p=0.001$ ). Mortality in positive residents of COVID-19 was significantly higher in those with a polypharmacy $>8$ and mini-mental state examination $<10$ points.

Conclusion: This study highlights the vulnerability of older adults to COVID-19 infection associated with high mortality and their global deterioration in the post-infection stage. Likewise, mortality in our population was higher in those with polypharmacy and cognitive impairment. These results guide us to create preventive measures that improve the quality and survival of geriatric COVID-19 patients.

Keywords: COVID-19, comprehensive geriatric assessment, older adults, long-term care facilities

\section{Introduction}

Coronavirus disease-2019 (COVID-19) has had a devastating impact in Mexico, ranking among the top five countries most affected by the virus with $10.4 \%$ in an observed case-fatality ratio (vs 2.8\% in the United States) and 65.56 deaths per 100,000 people (vs 64.74 per 100,000 in the United States) (1). By August 2021, Mexican government statistics have reported 1,637,836 excess deaths, from which it is estimated that 360,034 were caused by COVID-19; this represents an increase of $44.2 \%$ in the excess mortality (2). Of these deaths, 910,464 were found within the population over 65 years of age, resulting in an excess mortality of $41.2 \%$. These data are similar to the ones reported in the State of Nuevo León (42.4\%) and, unfortunately, a significant percentage of these deaths do not have a confirmatory test for a severe acute respiratory syndrome-coronavirus-2 (SARS-CoV-2) infection (2).

In March 2020, the first COVID-19 case was confirmed in Monterrey, Mexico. By August 12, 2021, the State of Nuevo Leon statistics reported 138,406 accumulated cases and 11.780

Address for Correspondence: Fernando Coindreau Frias, Geriatrics/Medical Director Casa de Reposo Luis Elizondo A.C. Guadalupe, Nuevo León, México Phone: +528183544865 E-mail: fcoindreau@gmail.com ORCID: orcid.org/0000-0002-8713-5260

Received: 18.11.2021 Accepted: 29.12.2021

Cite this article as: Coindreau-Frias F, Garza-Rivera JDD, Fernández-Garza LE, Valero-Gomez J. Comprehensive Geriatric Assessment in a Mexican Long-term Care Facility During a COVID-19 Outbreak. Eur J Geriatr Gerontol 2022;4(2):64-70

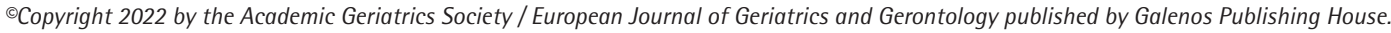


deaths due to COVID-19 (3). Of these, 138 infections in older adults occurred in multiple long-term care facilities (LTCF's) in Monterrey; nonetheless, data have not been updated in months. A potential reason is that most of these institutions are private and are afraid that the government regulatory bodies will close down the facilities (3).

Evidence has shown an exponential mortality increase in patients over 50 years; therefore, there has been an emphasis on protecting LCTF's residents since early in the pandemic (4). However, research on LTCF's is limited (5). In the United States, by May 21, 2021, over 35,000 deaths have been reported in LTCF's, representing $42 \%$ of total deaths due to COVID-19; LTCF's with more than 50 residents are the most affected (6). A study published in September 2020 reported that the mortality in 12 member countries of the organization for economic cooperation and development was $47.3 \%$ in LTCF's and 44.7\% in older adults living in the community (7). In addition to the greater risk in the elderly population, it is extremely important to consider the frailty syndrome in this population, since mortality reaches up to $33.7 \%$ in frail adults infected by COVID-19 (8).

Literature on COVID-19 infections at LCTF's and their postinfection impact on the elderly measured by the comprehensive geriatric assessment (CGA) in Mexico is scarce. Therefore, this study aims to i) Describe the COVID-19 outbreak in a LTCF in Monterrey, ii) Recognize factors that could have influenced the transmission of the SARS-CoV-2 and the mortality caused by COVID-19, and iii) Measure geriatric assessments after residents re-entry to the LTCF.

\section{Materials and Methods}

An observational, prospective study was carried out in a LCTF in Monterrey, Mexico. The CGA was evaluated in two stages: 1) In May 2020, representing the period patients received a confirmatory COVID-19 active infection, and 2) After their readmission to the LTCF in July 2020. The SARS-CoV-2 infection was confirmed through a reverse transcription-polymerase chain reaction test. Nuevo Leon's Health Ministry collected and processed COVID-19 tests.

Residents' socio-demographic characteristics and medical history were collected from patients' health records. Participants' functional status was evaluated using the Barthel index (BI) to measure their performance on activities of daily life (ADLs) (9), cognitive status was evaluated with Folstein's mini-mental state examination (MMSE) (10), and emotional status was measured according to the geriatric depression scale (GDS) (11). Additionally, we evaluated the participants' nutritional status using the mini nutritional assessment (MNA), including their measurements to calculate their body mass index (BMI) (12). Polypharmacy was also evaluated and defined as patients receiving a prescription of 8 or more drugs (13).

\section{Statistics}

Statistical analysis was done by IBM SPSS v22 software. Continuous variables are presented as the median and interquartile range or mean \pm standard deviation. Categorical variables are described as frequencies with their respective percentages (\%). The distribution of numeric variables was measured with the Kolmogorov-Smirnov test. Differences between groups were evaluated using the Mann-Whitney $\mathrm{U}$ test for numeric variables without a normal distribution, while the student t-test for independent groups was used for numeric variables with a normal distribution. The Wilcoxon test and the paired t-test were used for numeric variables with a non-normal and normal distribution, respectively, to evaluate the differences before the outbreak and after the patients' readmission. Differences in proportions were evaluated with the chi-square test. A binary logistic regression was performed adjusting for age and sex and including all the variables with a $p$-value $<0.1$ in the bivariate analysis. Statistical significance was defined as a $p$-value $<0.05$.

\section{Results}

Ninety patients were examined prior to the COVID-19 outbreak. The mean age was $84.71 \pm 7.47$, and the range was $67-101$ years. Sixty-one $(67.8 \%)$ were females and twenty-nine $(32.2 \%)$ males. The median outcome of the Bl evaluation was 80 (38.75-95), and $17(18.9 \%)$ patients were classified as totally dependent. The cognitive evaluation resulted in a median MMSE of 21 (1326); 29 (65.4\%) patients had a degree of cognitive impairment. The median GDS score was 4 (2-6); 21 (23.3\%) were classified as having depression. Finally, patients' nutritional status had a mean weight of $57.66 \pm 14.46 \mathrm{~kg}$, with a mean BMl of $23.7 \pm 4.6$ and a median MNA of $23(19.25-25) .33$ (36.7\%) were underweight, $19(21.1 \%)$ were overweight or obese, 39 (43.3\%) were at risk of malnutrition, and 11 (12.2\%) were malnourished.

The median of prescribed drugs was 6 (4-9) and 30 (33.3\%) residents reported having polypharmacy. The most frequently prescribed drug groups were antidepressants in 52 (57.8\%), acetylsalicylic acid in 35 (38.9\%), and lipid-lowering drugs in 33 (36.7\%) (Table 1). Regarding chronic degenerative diseases, $52(57.8 \%)$ were hypertensive, 24 (27.7\%) were diabetic, and 25 (27.8\%) had hypercholesterolemia. Since March 2020, 49 (54.4\%) residents have taken vitamin C $1.000 \mathrm{mg}$ and zinc 50 mg daily.

On May 2, 2020, 5 people (two staff and three residents) reported fever. The following day, six additional residents reported fever, and health authorities were notified. On May 4, 10 residents had a positive test for COVID-19, and in the next 24 hours, over 50 COVID-19 tests from people within the LTCF were positive. Consequently, all residents were transferred to different healthcare facilities. On May 9, 2020, the staff positive 


\section{Table 1. Baseline characteristics of residents before the outbreak \\ Socio-demographic features}

Age, mean $\pm S D$, years

\begin{tabular}{|l|r|}
\hline Sex, female & 61 \\
\hline $\mathrm{BI}$, median (IQR) & 80 \\
\hline $\mathrm{BI}>90$ & 36 \\
\hline
\end{tabular}

\begin{tabular}{|l|l|}
\hline BI 61-90 & 21 \\
\hline BI $21-60$ &
\end{tabular}

\begin{tabular}{|l|l|}
\hline $\mathrm{BI} 21-60$ & 16 \\
\hline $\mathrm{BI}<21$ & 17 \\
\hline
\end{tabular}

\begin{tabular}{|l|l|}
\hline MMSE, median (IOR) \\
\hline MMSE $>24$
\end{tabular}

\begin{tabular}{|l|l|}
\hline MMSE $17-24$ & 29 \\
\hline MMSE $10-16$ & 15
\end{tabular}

\begin{tabular}{|l|l|}
\hline MMSE $10-16$ & $15(16.7)$ \\
\hline MMSE $<10$ & $15(16.7)$ \\
\hline GDS, median (IQR) & $4(2-6)$ \\
\hline GDS $>5$ & $21(23.3)$ \\
\hline
\end{tabular}

\begin{tabular}{|l|l|}
\hline MNA, median (IQR) & $23(19.25-25)$ \\
\hline MNA 24-30 & $36(40)$ \\
\hline
\end{tabular}

\begin{tabular}{|l|l|}
\hline MNA 17-23.5 & $36(40)$ \\
\hline MNA $<17$ & $11(12.2)$ \\
\hline
\end{tabular}

\begin{tabular}{|l|l|}
\hline Weight, mean $\pm \mathrm{SD}, \mathrm{kg}$ & $57.66 \pm 14.46$ \\
\hline $\mathrm{BMI}$, mean $\pm \mathrm{SD}, \mathrm{kg} / \mathrm{m}^{2}$ & $23.7 \pm 4.6$ \\
\hline $\mathrm{BMI}<18.5$ & $9(10)$ \\
\hline
\end{tabular}

\begin{tabular}{|l|l|}
\hline $\mathrm{BMI}<18.5$ & $9(10)$ \\
\hline $\mathrm{BMI}>24.9$ & $33(36.7)$ \\
\hline Arterial hypertension & $52(57.8)$ \\
\hline
\end{tabular}

\begin{tabular}{|l|l|}
\hline Type 2 diabetes mellitus & $52(57.8)$ \\
\hline Hypercholesterolemia & $24(27.7)$ \\
\hline Medications, median (IOR) & $25(27.8)$ \\
\hline Polypharmacy & $6(4-9)$ \\
\hline
\end{tabular}

\begin{tabular}{|l|l|}
\hline Polypharmacy & $6(4-9)$ \\
\hline Antidepressants & $30(33.3)$ \\
\hline Acetylsalicylic acid & $52(57.8)$ \\
\hline
\end{tabular}

\begin{tabular}{|l|l|}
\hline Lipid-lowering agents & $35(38.9)$ \\
\hline PPI & $33(36.7)$ \\
\hline ACE inhibitors & $31(34.4)$ \\
\hline
\end{tabular}

\begin{tabular}{|l|l|}
\hline ACE inhibitors & $26(28.9)$ \\
\hline Benzodiazepines & $25(27.8)$ \\
\hline ARBs & $23(25.6)$ \\
\hline Antipsychotics & $22(24.4)$ \\
\hline Analgesics & $20(22.2)$ \\
\hline Oral antidiabetics & $16(17.8)$ \\
\hline Anti-dementia & $15(16.7)$ \\
\hline Diuretics & $12(13.3)$ \\
\hline Insulin & $10(11.1)$ \\
\hline Antiprostatic hypertrophy agents & $10(11.1)$ \\
\hline Beta-blockers & $7(7.8)$ \\
\hline Oral contraceptives & $3(3.3)$ \\
\hline SD:Standaris
\end{tabular}

SD: Standard deviation, BI: Barthel index, MMSE: Mini-mental state examination, GDS: Geriatric depression scale, MNA: Mini nutritional assessment, BMI: Body mass index, PPI: Proton-pump inhibitors, ACE: Angiotensin-converting enzyme, ARBs: Angiotensin II receptor blockers for COVID-19 was isolated in a shelter, and the 90 residents were taken to different medical units, separating the positive cases from the negatives. As for the residents with a positive test for COVID-19, 41 (62.1\%) were transferred to private centers, 22 $(33.3 \%)$ to public centers, and $3(4.5 \%)$ to their homes.

Out of the 90 residents (R), $66(73.3 \%)$ had a positive test for COVID-19 $(\mathrm{R}+)$ and $24(26.6 \%)$ a negative one (R-). When comparing both groups, the $\mathrm{R}+$ group had a lower mean age, fewer women, and a lower vitamin $\mathrm{C}$ and zinc intake; however, none of these differences resulted in a statistically significant p-value (Table 2). Further, we found a BI median of 90 (50-100) in the $\mathrm{R}+$ group and of 45 (16.25-92.5) in the R- group, suggesting that a greater independence in the ADLs, greater the risk for contagion $(p=0.003)$. Similarly, when evaluating the cognitive status, we observed a median MMSE in the $\mathrm{R}+$ group of 23 (15.75-27) and of 15 (1-23.75) in the R- group, suggesting that a higher cognitive performance, the greater the risk of infection $(p<0.001)$. The nutritional assessment resulted in a median of MNA in the R+ group of 23.5 (21-25.5) and 18.5 (16.62-24) in the $\mathrm{R}$ - group, suggesting that a higher MNA result, greater is the risk of infection $(p=0.006)$. The $B M I$ was higher in the $\mathrm{R}+$ group $(23.9 \pm 3.81$ vs $23.19 \pm 6.28)$; however, statistical significance was not reached $(p=0.524)$. Nonetheless, a higher proportion of lowweight residents was found in the R- group ( $p=0.010)$. The GDS score and weight were higher in the $\mathrm{R}+$; however, no statistically significant difference was observed. In addition, the proportions of residents with polypharmacy, hypertension, diabetes, and hypercholesterolemia were higher in the $\mathrm{R}+$ group without reaching a statistically significant difference (Table 2).

Of the 90 residents, 26 (28.9\%) died, 20 before returning to the LTCF, and six within the five months after returning. Out of the residents who died, the majority were women ( $57.7 \%$ vs $42.3 \%$; $p=0.192)$ and were $R+(80.8 \%$ vs $19.2 \% ; p=0.309)$. Participants were most frequently admitted to a public medical centre $(57.1 \%$ vs $42.9 \%)$, with patients treated in a private medical facility reporting fewer deaths $(p=0.008)$.

From June 15, 2020, residents started to return to the LTCF. By October 1, 2020, there were 59 residents due to the relatives' decision of $5(7.8 \%)$ not to return. Out of the 59 residents, 17 (28.8\%) were R- and 42 (71.2\%) R+; 41 (69.5\%) women and 18 $(30.5 \%)$ male. When evaluating participants with the CGA, we compared the results between the $\mathrm{R}+$ survivors and those who died, 20\% had an MMSE $<10$ ( $p=0.048), 60 \%$ had polypharmacy $(p=0.030)$, and the rest of the variables were not statistically significant (Table 3). In addition, the CGA was compared with the assessment prior to the outbreak, finding that after readmission to the LTCF, there was a greater functional dependence in the ADLs $(p<0.001)$, lower cognitive performance $(p<0.001)$, a higher score on the GDS ( $p=0.007)$, a lower nutritional status $(p<0.001)$ and a lower BMI $(p=0.009)$ in the residents (Table 4$)$. 


\begin{tabular}{|l|l|l|l|}
\hline \multicolumn{4}{|l}{$\begin{array}{l}\text { Table 2. Comparison of residents } \\
\text { negative (R-) test for SARS-CoV-2 }\end{array}$} \\
\hline & R+ (n=66) & \multicolumn{1}{l|}{ R- (n=24) } & p-value \\
\hline Age & $84.14 \pm 7.64$ & $86.29 \pm 6.9$ & 0.228 \\
\hline Sex, female & $42(63.6 \%)$ & $19(79.2 \%)$ & 0.163 \\
\hline Vitamin C + zinc & $35(53 \%)$ & $14(58.3 \%)$ & 0.655 \\
\hline BI & $90(50-100)$ & $45(16.25-92.5)$ & $0.003^{*}$ \\
\hline BI >90 & $30(45.5 \%)$ & $6(25 \%)$ & 0.079 \\
\hline BI <21 & $7(10.6 \%)$ & $10(41.7 \%)$ & $<0.001^{*}$ \\
\hline MMSE & $23(15.75-27)$ & $15(1-23.75)$ & $<0.001^{*}$ \\
\hline MMSE <10 & $7(7.6 \%)$ & $10(41.7 \%)$ & 0.101 \\
\hline GDS & $4(2-6)$ & $4(2-5)$ & 0.694 \\
\hline GDS >5 & $18(27.2 \%)$ & $3(12.5 \%)$ & 0.142 \\
\hline Weight & $58.86 \pm 10.62$ & $54.55 \pm 21.44$ & 0.217 \\
\hline BMI & $23.9 \pm 3.81$ & $23.19 \pm 6.28$ & 0.524 \\
\hline BMI <22 & $19(28.7 \%)$ & $14(58.3 \%)$ & $0.010^{*}$ \\
\hline MNA & $23.5(21-25.5)$ & $18.5(16.62-24)$ & $0.006^{*}$ \\
\hline MNA <17 & $5(7.57 \%)$ & $6(25 \%)$ & $0.025^{*}$ \\
\hline $\begin{array}{l}\text { Number of prescribed } \\
\text { drugs }\end{array}$ & $7(4-9)$ & $4(2.25-8.5)$ & 0.113 \\
\hline Polypharmacy & $24(36.4 \%)$ & $6(25 \%)$ & 0.312 \\
\hline Hypertension & $40(60.6 \%)$ & $12(50 \%)$ & 0.368 \\
\hline $\begin{array}{l}\text { Type 2 diabetes } \\
\text { mellitus }\end{array}$ & $21(31.8 \%)$ & $3(12.5 \%)$ & 0.067 \\
\hline Hypercholesterolemia & $28(42.4 \%)$ & $9(37.5 \%)$ & 0.675 \\
\hline $\begin{array}{l}\text { BI: Barthel index, MMSE: Mini-mental state examination, GDS: Geriatric depression } \\
\text { scale, MNA: Mini nutritional } \\
\text { acute respiratory syndrome-corsment, BMI: Body mass index, SARS-CoV-2: Severe }\end{array}$ \\
\hline
\end{tabular}

Lastly, the binary logistic regression did not show a statistically significant value between the included variables and the risk for infection. However, having an MMSE $<10$ and reporting polypharmacy increased the risk of mortality in the $\mathrm{R}+$ group by 11 and 4 times more, respectively (Table 5).

\section{Discussion}

To the authors' knowledge, this is the first study in Mexico that evaluates the impact of COVID-19 on LTCFs using the CGA and compares the physical, psycho-affective, mental, and nutritional status before and after a COVID-19 outbreak. The LTCF evaluation has been characterized by providing daily rehabilitation services to the patients from their admission to the unit, fostering the preservation and improvement of the physical, cognitive, and emotional health according to the individual resident's needs.

Among the residents of the LTCF, 66 of them were diagnosed with COVID-19, and 15 died, resulting in an attack rate of $73.3 \%$ and a fatality rate of $22.7 \%$. Similar results were observed compared to studies in different European countries, where attack rates in nursing homes long stay due to COVID-19 outbreaks oscillated in 60\% and the fatality rates have been between 15 and 34\%
Table 3. Comparison between the residents with a positive COVID-19 who survived ( $R+$ survivors) and died ( $R+$ deceased)

\begin{tabular}{|l|l|l|l|}
\hline & $\begin{array}{l}\text { R+ survivors } \\
\text { (n=48) }\end{array}$ & $\begin{array}{l}\text { R+ deceased } \\
\text { (n=15) }\end{array}$ & p-value \\
\hline Age & $83.79 \pm 7.82$ & $85.2 \pm 7.02$ & 0.536 \\
\hline Sex, women & $31(64.6 \%)$ & $8(53.3 \%)$ & 0.434 \\
\hline Vitamin C + zinc & $27(56.3 \%)$ & $5(33.3 \%)$ & 0.121 \\
\hline BI & $90(61.25-100)$ & $80(40-95)$ & 0.148 \\
\hline BI >90 & $23(47.9 \%)$ & $6(40 \%)$ & 0.591 \\
\hline BI <21 & $4(8.3 \%)$ & $3(20 \%)$ & 0.209 \\
\hline MMSE & $23(18-27)$ & $21(11-25)$ & 0.228 \\
\hline MMSE <10 & $2(4.2 \%)$ & $3(20 \%)$ & $0.048^{*}$ \\
\hline GDS & $4(2-5.5)$ & $5(2-9)$ & 0.446 \\
\hline GDS >5 & $11(24.4 \%)$ & $6(46.2 \%)$ & 0.129 \\
\hline Weight & $59.93 \pm 10.53$ & $56.02 \pm 10.57$ & 0.230 \\
\hline BMI & $23.55 \pm 5.27$ & $23.41 \pm 3.29$ & 0.925 \\
\hline BMI <22 & $14(31.1 \%)$ & $4(28.6 \%)$ & 0.857 \\
\hline MNA & $24(21-25.5)$ & $23(20-24.25)$ & 0.260 \\
\hline MNA <17 & $4(8.9 \%)$ & $1(7.1 \%)$ & 0.838 \\
\hline $\begin{array}{l}\text { Number of prescribed } \\
\text { drugs }\end{array}$ & $7(4-8.75)$ & $9(4-10)$ & 0.150 \\
\hline Polypharmacy & $14(29.2 \%)$ & $9(60 \%)$ & $0.030^{*}$ \\
\hline Hypertension & $30(62.5 \%)$ & $9(60 \%)$ & 0.862 \\
\hline $\begin{array}{l}\text { Type 2 diabetes } \\
\text { mellitus }\end{array}$ & $14(29.2 \%)$ & $6(40 \%)$ & 0.431 \\
\hline Hypercholesterolemia & $20(41.7 \%)$ & $8(53.3 \%)$ & 0.427 \\
\hline $\begin{array}{l}\text { CovID-19: Coronavirus disease-2019, BI: Barthel } \\
\text { examination, GDS: Geriatric depression scale, MNA: Mini nutritional assessment, BMI: } \\
\text { Body mass index, }{ }^{*} \text { p-value }<0.05 \text { is statistically significant }\end{array}$ \\
\hline
\end{tabular}

Table 4. Comparison of residents' performance prior to the outbreak and after their readmission to the LTCF

\begin{tabular}{|l|l|l|l|}
\hline & $\begin{array}{l}\text { Prior the } \\
\text { outbreak }\end{array}$ & After readmission & p-value \\
\hline BI & $90(45-100)$ & $57.5(10-95)$ & $<0.001^{*}$ \\
\hline MMSE & $23(13-27)$ & $19(11-26)$ & $<0.001^{*}$ \\
\hline GDS & $4(2-5)$ & $5(3-7)$ & $0.007^{*}$ \\
\hline Weight & $59.63 \pm 15.41$ & $56.95 \pm 14.93$ & $<0.001^{*}$ \\
\hline BMI & $23.9 \pm 4.85$ & $23.19 \pm 4.83$ & $0,009^{*}$ \\
\hline MNA & $23(19.75-25.5)$ & $21.5(18.75-23.12)$ & $<0.001^{*}$ \\
\hline $\begin{array}{l}\text { Number of } \\
\text { prescribed drugs }\end{array}$ & $6(4-9)$ & $6.5(4-8.25)$ & 0.246 \\
\hline $\begin{array}{l}\text { BI: Barthel index, MMSE: Mini-mental state examination, GDS: Geriatric depression } \\
\text { scale, MNA: Mini nutritional assessment, BMI: Body mass index, }{ }^{*} \text { a p-value }<0.05 \text { is } \\
\text { statistically significant, LTCF: Long-term care facilities }\end{array}$ \\
\hline
\end{tabular}

$(14,15)$. This demonstrates the increase in mortality that has been described with increasing age (16).

A significantly higher incidence of COVID-19 cases was detected in older adults with low physical dependence in the ADLs, with a median BI of 90 (50-100) in residents with COVID-19. This could 
Table 5. Regression analysis of factors that increased the risk of transmission and mortality due to COVID-19 OR $95 \% \mathrm{Cl}$ p-value Variables related to an increased risk of COVID-19 infection

\begin{tabular}{|l|l|l|l|}
\hline $\mathrm{BI}<21$ & 0.466 & $0.081-2.675$ & 0.392 \\
\hline $\mathrm{MMSE}$ & 1.051 & $0.971-1.137$ & 0.217 \\
\hline $\mathrm{BMI}<22$ & 0.621 & $0.157-2.466$ & 0.499 \\
\hline $\mathrm{MNA}$ & 1.026 & $0.816-1.292$ & 0.824 \\
\hline Type 2 diabetes mellitus & 2.142 & $0.489-9.386$ & 0.312 \\
\hline
\end{tabular}

Variables related to an increased risk of COVID-19 mortality

\begin{tabular}{|l|l|l|l|}
\hline MMSE $<10$ & 11.111 & $1.369-90.909$ & $0.024^{*}$ \\
\hline Polypharmacy & 4.651 & $1.218-17.765$ & $0.025^{*}$ \\
\hline
\end{tabular}

COVID-19: Coronavirus disease-2019, BI: Barthel index, MMSE: Mini-mental state examination, MNA: Mini nutritional assessment, BMI: Body mass index, Cl: Confidence interval, OR: Odds ratio, *a p-value $<0.05$ is statistically significant

be related to the route of transmission of the virus: Mainly from person to person (staff-residents), and the increased social contact in adults with greater functionality. Compared to Spanish LTCF's, where residents with moderate to total dependence were more vulnerable to the risk of transmission of SARS-CoV-2, associated with closer physical contact between workers and residents, facilitating transmission (17). Likewise, significant results were found when evaluating the functionality in ADLs before and after the COVID-19 outbreak at the facility, finding a considerable 32.5 decrease in the $\mathrm{BI}$ median. This decrease might be the consequence of the length of stay, functional depression, and the need for restrictive mobility in most of them, thus increasing dependency (18).

A significant cognitive decline (4-point median MMSE score decrease) was found in COVID-19 positive older adults after readmission to the LTCF. It is important to emphasize that progress to a moderate cognitive impairment was observed in the vast majority of the residents. Moreover, higher mortality was found in residents with a positive test for COVID-19 and an MMSE $<10$ points. Post-acute manifestations have been described as associated with cognitive impairment with or without fluctuations, including memory problems manifesting as difficulty in concentration, memory, receptive language, and/ or executive function (19). Furthermore, long-term cognitive impairment is well recognized after a critical illness occurring up to $20-40 \%$ of patients discharged from intensive care (20).

Regarding the affective mood behaviour, we found a significant change in the GDS-15 scale items of the residents evaluated after returning to the institution, resulting in an overall median increase of 4 to 5 points, considering that most of the residents before the pandemic did not report symptoms of depression. Our results coincide with studies where depression, measured with the same instrument, was exacerbated by up to $86.6 \%$ two weeks after being discharged from the hospital in patients aged 65 or older who survived COVID-19 (21). Demonstrating that social disconnection and isolation are risk factors for presenting a depressive mood in older adults (22).

Concerning nutritional status of the residents, a significantly higher proportion of underweight and malnutrition was observed in the non-infected residents. This aligns with the explanation that the highly dependent population in the ADLs with a higher risk of sarcopenia has less mobilization and less social contact with other residents and staff; thus, reducing the risk of infection. Similarly, a significant change was observed in the decrease in residents' weight, BMI, and MNA after the COVID-19 outbreak. For these reasons, it is vital to identify and prevent a nutritional decline in hospitalizations and improve clinical outcomes in patients at nutritional risk. It has been found that the MNA-SF (short-form) scale predicted in a good way the worst clinical results after COVID-19 infection (23). On the other hand, when using the MNA scale in full version in patients with COVID-19, found a positive correlation between poor nutritional status and a prolonged stay in the intensive care unit (24).

It was observed that polypharmacy was significantly associated with higher mortality in residents who tested positive for COVID-19. Sixty percent of the residents who died had polypharmacy, and the regression analysis resulted in four times the risk of dying in this sub-group compared to the rest of the residents with COVID-19. Polypharmacy has unpredictable consequences as cohort studies reported that up to $50 \%$ of American older adults use at least five drugs, of which 1 in 2 have been found to have significant interactions with drugs tested for COVID-19, such as hydroxychloroquine (25). In the REACT-SCOT study, an evident association was found between the severity of COVID-19 and polypharmacy, mainly in using more than four drugs of different classes. In addition, it was found that the severity of the infection is strongly associated with antipsychotics, proton pump inhibitors, opioids, and gabapentinoids, since an increase in activity associated with pneumonia has been found by different routes, mainly anticholinergic and by mechanisms that increase the severity such as sedation, respiratory depression, and dyskinesia (26).

Among the chronic-degenerative diseases, we found a statistical trend between the presentation of COVID-19 and type 2 diabetes mellitus (27). This could be explained by the alterations in the expression of the surface receptors of the converting enzyme angiotensin 2, which has a binding region with a high affinity for the S protein of the SARS-CoV-2 virus (28). In addition, there is a dysregulation of the immune system due to the increase in interleukin- 6 and the weakening of anti-inflammatory signals producing more significant damage to the affected organs (29). On the other hand, a meta-analysis found that hypertension and diabetes are highly associated with an increase in severity and mortality from COVID-19 of 2.3 and 2.5 times, respectively (30). 


\section{Study Limitations}

Our study had limitations worth mentioning: we do not know the evolution that the patients had during their infection and what could have influenced their outcome (e.g., clinical evolution, possible complications, laboratory findings, received treatment, and whether or not they received any rehabilitation). It is important to emphasize that a significantly lower mortality rate was found in private medical centers than public ones, which would be associated with better availability of human, pharmacological, and medical devices resources. Lastly, the results should be interpreted with caution due to the size of the study group.

\section{Conclusion}

The COVID-19 pandemic, as observed in other countries and Mexico, not being the exception, confirms the vulnerability in the functional, cognitive, emotional, and nutritional aspects of the elderly. An essential factor to consider is that most of the residents evaluated in this study who were positive cases were patients with a better global status in all indicators considered in the study, which would be associated with a greater risk of infection. In our population, we found higher mortality in residents with polypharmacy and with an MMSE $<10$ points. In addition, a significant change was found in functional dependence in the ADLs, cognitive impairment, emotional mood changes and nutritional status after the COVID-19 outbreak in the LTCF. Currently and with the growing information that we have about COVID-19, changes are needed in the CGA to provide measures that promote preventive, diagnostic, and therapeutic options to preserve and improve the quality of life and even decrease mortality in the elderly associated with COVID-19 infection.

\section{Ethics}

Ethics Committee Approval: The Ethics Committee of Asilo Luis Elizondo through its members of the Council formed by Fomento Moral y Educativo A.C. authorized the preparation of this manuscript entitled: Comprehensive Geriatric Assessment in a Mexican Long-Term Care Facility during a COVID-19 Outbreak.

Informed Consent: All the relatives and residents of the Asilo Luis Elizondo upon admission sign an informed consent on the use of their personal and clinical data to carry out clinical research work.

Peer-review: Externally peer-reviewed.

\section{Authorship Contributions}

Surgical and Medical Practices: F.C.F., J.D.D.G.R., L.E.F.G., J.V.G., Concept: F.C.F., J.D.D.G.R., L.E.F.G., J.V.G., Design: F.C.F., J.D.D.G.R., L.E.F.G., J.V.G., Data Collection or Processing: F.C.F., J.D.D.G.R., L.E.F.G., J.V.G., Analysis or Interpretation: F.C.F., J.D.D.G.R.,
L.E.F.G., J.V.G., Literature Search: F.C.F., J.D.D.G.R., L.E.F.G., J.V.G., Writing: F.C.F., J.D.D.G.R., L.E.F.G., J.V.G.

Conflict of Interest: No conflict of interest was declared by the authors.

Financial Disclosure: The authors declared that this study received no financial support.

\section{References}

1. Rivera-Hernandez M, Ferdows NB, Kumar A. The Impact of COVID-19 Epidemic on Older Adults in Rural and Urban Areas in Mexico. J Gerontol B Psychol Sci Soc 2021;76:e268-274.

2. Mejía LSP, Ávila HJE. Exceso de mortalidad en México. Available at: https://coronavirus.gob.mx/exceso-de-mortalidad-en-mexico/. Accesed on September 1, 2021.

3. Gobierno de Nuevo León. Casos de COVID-19 en Nuevo León. Available at: https://www.nl.gob.mx/publicaciones/casos-de-covid-19-en-nuevo-leon. Accesed on September 1, 2021.

4. Bonanad C., García-Blas S., Tarazona-Santabalbina F, Sanchis J, BertomeuGonzález V, Fácila L, Ariza A, Núñez J, Cordero A. The effect of age on mortality in patients with COVID-19: A meta-analysis with 611,583 subjects. J Am Med Dir Assoc 2020;21:915-918.

5. McMichael TM, Currie DW, Clark S, Pogosjans S, Kay M, Schwartz NG, Lewis J, Baer A, Kawakami V, Lukoff MD, Ferro J, Brostrom-Smith C, Rea TD, Sayre MR, Riedo FX, Russell D, Hiatt B, Montgomery P, Rao AK, Chow EJ, Tobolowsky F, Hughes MJ, Bardossy AC, Oakley LP, Jacobs JR, Stone ND, Reddy SC, Jernigan JA, Honein MA, Clark TA, Duchin JS; Public HealthSeattle and King County, EvergreenHealth, and CDC COVID-19 Investigation Team. Epidemiology of Covid-19 in a long-term care facility in King County, Washington. N Engl J Med 2020;382:2005-2011.

6. Abrams HR, Loomer L, Gandhi A, Grabowski DC. Characteristics of U.S. nursing homes with COVID-19 cases. J Am Geriatr Soc 2020;68:1653-1656.

7. Sepulveda ER, Stall NM, Sinha SK. A comparison of COVID-19 mortality rates among long-term care residents in 12 OECD Countries. J Am Med Dir Assoc 2020;21:1572-1574.e3.

8. Thompson DC, Barbu MG, Beiu C, Popa LG, Mihai MM, Berteanu M, Popescu MN. The impact of COVID-19 pandemic on long-term care facilities worldwide: An overview on international issues. Biomed Res Int 2020;2020:8870249.

9. Sainsbury A, Seebass G, Bansal A, Young JB. Reliability of the Barthel Index when used with older people. Age Ageing 2005; 34:228-232.

10. Folstein MF, Folstein SE, McHugh PR. "Mini-mental state". A practical method for grading the cognitive state of patients for the clinician. J Psychiatr Res 1975;12:189-198.

11. Wancata J, Alexandrowicz R, Marquart B, Weiss M, Friedrich F. The criterion validity of the Geriatric Depression Scale: a systematic review. Acta Psychiatr Scand 2006;114:398-410.

12. Guigoz $Y$, Lauque $S$, Vellas BJ. Identifying the elderly at risk for malnutrition. The mini nutritional assessment. Clin Geriatr Med 2002;18:737-757.

13. Sganga $F$, Landi $F$, Ruggiero $C$, Corsonello $A$, Vetrano $D L$, Lattanzio $F$, Cherubini A, Bernabei $R$, Onder G. Polypharmacy and health outcomes among older adults discharged from Hospital: results from the crime study. Geriatr Gerontol Int 2015;15:141-146.

14. Heras $E_{1}$ Garibaldi $P$, Boix $M$, Valero O, Castillo J, Curbelo $Y$, Gonzalez $E$, Mendoza O, Anglada, M, Miralles JC, Llull P, Llovera R, Piqué J. M. COVID-19 mortality risk factors in older people in a long-term care center. Eur Geriatr Med 2021;12:601-607.

15. Tarteret P, Strazzulla A, Rouyer M, Gore C, Bardin G, Noel C, Benguerdi ZE, Berthaud J, Hommel M, Aufaure S, Jochmans S, Diamantis, S. Clinical features 
and medical care factors associated with mortality in French nursing homes during the COVID-19 outbreak. Int J Infect Dis 2020;104:125-131.

16. Sharma A. Estimating Older Adult Mortality From COVID-19. J Gerontol B Psychol Sci Soc Sci 2021;76(3):e68-e74.

17. Causa R, Almagro Nievas D, Bermúdez Tamayo C. [COVID-19 and functional dependence: cohort study of an outbreak in a nursing home for elderly]. Rev Esp Salud Puublica 2021;95:e202103045..

18. Hoogerduijn JG, Schuurmans MJ, Duijnstee MS, de Rooij SE, Grypdonck MF. A systematic review of predictors and screening instruments to identify older hospitalized patients at risk for functional decline. J Clin Nurs 2007;16:46-57.

19. Crook H, Raza S, Nowell J, Young M, Edison P. Long covid-mechanisms, risk factors, and management. BMJ 2021;374:n1648.

20. Nalbandian A, Sehgal K, Gupta A, Madhavan MV, McGroder C, Stevens JS, Cook JR, Nordvig AS, Shalev D, Sehrawat TS, Ahluwalia N, Bikdeli B, Dietz D, Der-Nigoghossian C, Liyanage-Don N, Rosner GF, Bernstein EJ, Mohan S, Beckley AA, Seres DS, Choueiri TK, Uriel N, Ausiello JC, Accili D, Freedberg DE, Baldwin M, Schwartz A, Brodie D, Garcia CK, Elkind MSV, Connors JM, Bilezikian JP, Landry DW, Wan EY. Post-acute COVID-19 syndrome. Nat Med 2021; 27:601-615.

21. Mowla A, Ghaedsharaf M, Pani A. Psychopathology in Elderly COVID-19 Survivors and Controls. J Geriatr Psychiatry Neurol 2022;35:467-471.

22. Armitage R, Nellums LB. COVID-19 and the consequences of isolating the elderly. Lancet Public Health 2020;5:e256.

23. Liu G, Zhang S, Mao Z, Wang W, Hu H. Clinical significance of nutritional risk screening for older adult patients with COVID-19. Eur J Clin Nutr 2020;74:876-883.

24. Haraj NE, El Aziz S, Chadli A, Dafir A, Mjabber A, Aissaoui O, Barrou L, El Kettani El Hamidi C, Nsiri A, Al Harrar R, Ezzouine H, Charra B, Abdallaoui MS, El Kebbaj N, Kamal N, Bennouna GM, El Filali KM, Ramdani B, El Mdaghri N, Gharbi MB, Afif MH. Nutritional status assessment in patients with Covid-19 after discharge from the intensive care unit. Clin Nutr ESPEN 2021;41:423-428.

25. Ross SB, Wilson MG, Papillon-Ferland L, Elsayed S, Wu PE, Battu K, Porter S, Rashidi B, Tamblyn R, Pilote L, Downar J, Bonnici A, Huang A, Lee TC, McDonald EG. COVID-SAFER: Deprescribing Guidance for Hydroxychloroquine Drug Interactions in Older Adults. J Am Geriatr Soc 2020;68:1636-1646.

26. McKeigue PM, Kennedy S, Weir A, Bishop J, McGurnaghan SJ, McAllister D, Robertson C, Wood R, Lone N, Murray J, Caparrotta TM, Smith-Palmer A, Goldberg D, McMenamin J, Guthrie B, Hutchinson S, Colhoun HM; Public Health Scotland COVID-19 Health Protection Study Group. Relation of severe COVID-19 to polypharmacy and prescribing of psychotropic drugs: the REACT-SCOT case-control study. BMC Med 2021;19:51.

27. Bauer SR, Kapoor $A$, Rath $M$, Thomas SA. What is the role of supplementation with ascorbic acid, zinc, vitamin $\mathrm{D}$, or $\mathrm{N}$-acetylcysteine for prevention or treatment of COVID-19? Cleve Clin J Med 2020;10.3949/ccjm.87a.ccc046.

28. Thomas S, Patel D, Bittel B, Wolski K, Wang Q, Kumar A, II'Giovine ZJ, Mehra R, McWilliams C, Nissen SE, Desai MY. Effect of High-Dose Zinc and Ascorbic Acid Supplementation vs Usual Care on Symptom Length and Reduction Among Ambulatory Patients With SARS-CoV-2 Infection: The COVID A to Z Randomized Clinical Trial. JAMA Netw Open 2021;4:e210369.

29. Barrera FJ, Shekhar S, Wurth R, Moreno-Pena PJ, Ponce OJ, Hajdenberg M, Alvarez-Villalobos NA, Hall JE, Schiffrin EL, Eisenhofer G, Porter F, Brito JP, Bornstein SR, Stratakis CA, González-González JG, Rodíguez-Gutiérrez R, Hannah-Shmouni F. Prevalence of Diabetes and Hypertension and Their Associated Risks for Poor Outcomes in Covid-19 Patients. J Endocr Soc 2020;4:bvaa102.

30. de Almeida-Pititto B, Dualib PM, Zajdenverg L, Dantas JR, de Souza FD, Rodacki M, Bertoluci MC; Brazilian Diabetes Society Study Group (SBD). Severity and mortality of COVID 19 in patients with diabetes, hypertension and cardiovascular disease: a meta-analysis. Diabetol Metab Syndr 2020;12:75. 